\title{
Ensino de Espanhol na educação de jovens e adultos
}

Claudia de Souza Teixeira ${ }^{1}$, Simone de Lima ${ }^{2}$

\section{Resumo}

Este artigo tem como objetivo refletir sobre o ensino de Espanhol em turmas de Educação de Jovens e Adultos (EJA) do ensino médio. O referencial teórico está baseado em documentos de órgãos federais e em trabalhos sobre as funções da EJA, o perfil dos seus alunos, o papel dos professores, o ensino de língua estrangeira e, em especial, o de espanhol na EJA. Defende-se que problemas como a inadequação dos materiais e das abordagens, que dificultam a desconstrução de crenças negativas dos alunos da EJA quanto a aprender uma língua estrangeira, são agravados pelo fato de que esses educandos chegam à escola, em geral, inseguros quanto à sua capacidade de dominar novos conhecimentos formais. Além dos dados teóricos, são relatadas algumas experiências pedagógicas de uma das autoras deste trabalho, como professora de espanhol, em turmas de EJA do ensino médio, em que a contextualização das atividades e o diálogo com os alunos foram fatores preponderantes para a efetivação de um processo ensinoaprendizagem de qualidade. Ao final, tenta-se comprovar a importância do ensino de espanhol não só para o aumento dos conhecimentos e da autoestima dos educandos jovens e adultos, mas também para sua maior inclusão social.

\section{Palavras-chave}

Ensino de Espanhol. Educação de jovens e adultos. Inclusão social.

\footnotetext{
${ }^{1}$ Doutora em Letras Vernáculas pela Universidade Federal do Rio de Janeiro, Rio de Janeiro, Brasil; professora de Língua Portuguesa, Literatura e Metodologia da Pesquisa do Instituto Federal de Educação, Ciência e Tecnologia do Rio de Janeiro, Rio de Janeiro, Brasil. E-mail: claudia.teixeira@ ifrj.edu.br.

${ }^{2}$ Especialista em Educação de Jovens e Adultos pelo Instituto Federal de Educação, Ciência e Tecnologia do Rio de Janeiro, Campus Nilópolis, Rio de Janeiro, Brasil; professora de língua espanhola do Serviço Social da Indústria (SESI), Rio de Janeiro, Brasil. E-mail: schmitz.de.lima@globo.com.
} 


\title{
Teaching of Spanish in the young and adult people education
}

Claudia de Souza Teixeira ${ }^{3}$, Simone de Lima ${ }^{4}$

\begin{abstract}
This paper aims to reflect on the teaching of Spanish in high school classes of Young and Adult People Education (YAPE). The theoretical framework is based on documents of federal agencies and on works about the YAPE functions, its students' profile, the role of the teachers, the teaching of a foreign language and, in special, the teaching of Spanish. It is defended that problems such as the inadequacy of materials and of the approaches, that hinder the deconstruction of negative beliefs of YAPE students in learning a foreign language, are aggravated by the fact that these students come to school, in general, unsure about their ability to master new formal knowledge. In addition to the theoretical data, some pedagogical experiences of one of the authors of this study, as a Spanish teacher, in high school YAPE classes, where the contextualization of activities and the dialogue with students were preponderant factors for the implementation of a quality teaching-learning process, are related. Finally, based on the reflection about the results achieved with the reported activities, this study tries to prove the importance of teaching Spanish to increase not only the knowledge and self-esteem of young and adult learners, but also their social inclusion.
\end{abstract}

\section{Keywords}

Teaching of Spanish. Young and adult people education. Social inclusion.

\footnotetext{
${ }^{3} \mathrm{PhD}$ in Vernacular Letters, Federal University of Rio de Janeiro, State of Rio de Janeiro, Brazil; professor of Portuguese Language, Literature and Research Methodology at the Federal Institute of Education, Science and Technology of Rio de Janeiro, State of Rio de Janeiro, Brazil. E-mail: claudia.teixeira@ifrj.edu.br.

${ }^{4}$ Specialist in Youth and Adult Education, Federal Institute of Education, Science and Technology of Rio de Janeiro, Nilópolis Campus, State of Rio de Janeiro, Brazil; Spanish-speaking teacher of the Social Service of Industry (SESI), State of Rio de Janeiro, Brazil. E-mail: schmitz.de.lima@ globo.com.
} 


\section{Introdução}

Com base no referencial teórico e em experiências de uma das autoras com turmas do ensino médio da Educação de Jovens e Adultos (EJA-EM) em uma escola particular da cidade do Rio de Janeiro, este artigo reflete sobre o ensino de espanhol, nessa modalidade de ensino, e a sua contribuição para o aumento da autoestima dos alunos e para a formação integral deles.

Os educandos da EJA-EM são, normalmente, pessoas que retomam os estudos na esperança de conseguir uma vida melhor, e concluir o ensino médio é uma conquista que envolve grandes batalhas pessoais, exigindo superação e determinação. Portanto, embora a empatia do professor seja necessária em qualquer nível de ensino, é especialmente relevante na EJA, porque os alunos normalmente possuem dificuldades decorrentes do afastamento da escola, de reprovações, do trabalho, da idade, da baixa autoestima etc. Assim, a empatia, muitas vezes, será o diferencial para a permanência e bons resultados dos discentes.

Mais do que se preocupar com o conteúdo programático, o professor precisa se atentar para os efeitos não mensuráveis de sua ação pedagógica, como estímulo aos estudos, aumento da autoestima, ampliação da visão de mundo, enfim, a transformação pessoal que a educação poderá provocar. Ao planejar as aulas, é preciso ter em conta a experiência de vida dos alunos e, a partir daí, estimular a vontade de saber mais, tornando o conhecimento escolar algo significativo e relevante para eles.

Vivemos a era das novas tecnologias digitais, quando o conhecimento pode ser facilmente acessado pela internet a qualquer momento e em qualquer lugar. Assim, o professor precisa também ensinar seus alunos a selecionar informações de forma produtiva, sabendo interpretar, analisar e conectar essas informações com o mundo real para construir saberes que servirão como instrumento em sua relação com a sociedade.

O ensino de espanhol como língua estrangeira, nesse contexto, pode contribuir para a formação integral do aluno de EJA, como esclarece Paraquett (2009, p. 131):

Espera-se, então, que a aprendizagem de línguas estrangeiras ultrapasse o conhecimento da metalinguagem, assim como saia da esfera restrita da tecnologia e do mercado de trabalho, para se transformar em ferramenta de conhecimento, de autoconhecimento, de eliminação de fronteiras e, principalmente, de inclusão social.

Ainda segundo as Orientações Curriculares para o Ensino Médio (OCNEM), 
[...] o papel crucial que o conhecimento de uma língua estrangeira, de um modo geral e do espanhol em particular, pode ter nesse nível de ensino: levar o estudante a ver-se e constituir-se como sujeito a partir do contato e da exposição ao outro, à diferença, ao reconhecimento da diversidade. (BRASIL, 2006, p. 133).

Esse trabalho coaduna com as ideias de Gadotti (2011) sobre o papel do professor como educador e da emoção como fator preponderante no processo educativo, além dos pressupostos de Freire (1996) de que o ato de ensinar precisa partir do conhecimento prévio dos educandos e não pode prescindir da afetividade.

Para tratar de aspectos legais do ensino de língua estrangeira e, de maneira específica, do espanhol, são apresentadas, no desenvolvimento deste artigo, algumas determinações das leis n 9. 394/96 (BRASIL, 1996), n 11.161/05 (BRASIL, 2005) e nº 13.415 (BRASIL, 2017).

Com base em Barcelos (2007), procura-se mostrar que a língua estrangeira provoca uma reação inicial de rejeição por parte dos estudantes da EJA. A partir de Moraes (2010) e Paraquett (2009), são apontadas dificuldades enfrentadas pelos professores de espanhol no Brasil, como a falta de material didático adequado, a desvalorização da disciplina e as metodologias totalmente inadequadas. Pelas conclusões das pesquisas de Catta Preta (2008) e Labella-Sánchez (2012), é possível entender que as dificuldades do ensino de espanhol são ainda mais agravadas nas turmas de EJA devido à inadequação do material e, principalmente, da abordagem.

A todas essas dificuldades soma-se o fato de que os educandos dessa modalidade de ensino chegam à escola, em geral, com baixa autoestima, duvidando de sua capacidade de dominar os novos conhecimentos formais. Esse é, sem dúvida, um fator que precisa ser levado em conta pelo professor de língua estrangeira.

Contudo, mesmo descrevendo um panorama muitas vezes desfavorável ao professor de espanhol, este artigo mostra os resultados positivos de algumas atividades realizadas por uma das autoras com turmas de EJA-EM, nas quais a contextualização e o diálogo com os alunos foram essenciais.

\section{Referencial teórico}

Nesta parte do trabalho são apresentadas as principais características dos alunos de EJA, assim como alguns aspectos do ensino de espanhol na EJA-EM. 


\section{Os alunos da EJA}

Segundo o Parecer CNE/CEB 11/2000, é fundamental que o professor da EJA se prepare para um grupo de alunos diferentes daqueles que compõem uma turma de ensino regular:

[...] pode-se dizer que o preparo de um docente voltado para a EJA deve incluir, além das exigências formativas para todo e qualquer professor, àquelas relativas à complexidade diferencial desta modalidade de ensino. Assim, esse profissional do magistério deve estar preparado para interagir empaticamente com esta parcela de estudantes e de estabelecer o exercício do diálogo. (BRASIL, 2000, p. 52).

Nas turmas de EJA, o educador precisa ter em mente que os educandos, mesmo os adultos, desenvolvem continuamente conhecimentos, competências e atitudes, dentro e fora da escola. Conforme afirma Freire (2000, p. 40): "Esse processo de formação perdura ao longo da vida toda, o homem não para de educar-se, sua formação é permanente e se funda na dialética entre teoria e prática".

Os alunos da EJA trazem variados tipos de experiências prévias; conhecimentos relacionados à vida profissional, política, social; valores morais, religiosos, culturais, entre outros, e, muitas vezes, carregam visões preconceituosas que precisam ser revistas, cabendo à escola um papel transformador.

Tendo acesso ao conhecimento formal, os alunos são estimulados a ampliar seus horizontes, repensar suas crenças equivocadas e, nesse processo, crescer como cidadãos e indivíduos, aperfeiçoando sua atuação na sociedade, aprendendo a questionar, reivindicar, exigir o que lhes foi negado e o que é seu por direito: uma educação de qualidade.

A EJA é momento significativo de reconstruir estas experiências da vida ativa e ressignificar conhecimentos de etapas anteriores da escolarização, articulando-os com os saberes escolares. A validação do que se aprendeu "fora" dos bancos escolares é uma das características da flexibilidade responsável que pode aproveitar estes "saberes" nascidos destes "fazeres". (BRASIL, 2000, p. 31)

Em todos os níveis de ensino, os alunos precisam ser conquistados cognitiva e emocionalmente. No caso da EJA, no entanto, essa conquista, muitas vezes, é uma tarefa mais complexa, considerando as crenças de muitos alunos de que têm dificuldades de adquirir conhecimentos formais. Porém, ao se estabelecerem os vínculos de confiança entre o professor e os educandos, é possível se chegar a resultados relevantes, tanto para os alunos como para o próprio professor, que consegue perceber a si mesmo como um profissional de grande potencial transformador. 


\section{O ensino de espanhol na EJA-EM}

No ensino de língua estrangeira, faz-se necessária a desconstrução de algumas crenças (BARCELOS, 2007) que normalmente o aluno de EJA traz consigo, tais como: "aprender idiomas é muito difícil", "só se aprende língua estrangeira em cursos de idiomas", "não tenho inteligência suficiente para aprender idiomas”. Essas crenças são repetidas como verdades, e os alunos tendem a nem querer tentar aprender, rejeitando o conhecimento num primeiro contato com a língua estrangeira.

Barcelos (2007) afirma que a reflexão é o caminho para que o professor, mudando suas práticas, consiga também provocar mudanças nos alunos. Ela defende que

[...] é importante que haja espaço e oportunidade tanto para alunos quanto para professores para desafio e questionamento das crenças, para que assim possam surgir "momentos catalisadores de reflexão", ou seja, "gatilhos" promotores de problemas, dúvidas ou perguntas que geram uma consciência da crença existente e seu possível questionamento no dizer e no fazer. (BARCELOS, 2007, p. 127).

Cabe ao professor reconstruir essas impressões para que os alunos se percebam capazes de aprender outro idioma como conhecimento válido e acessível a eles, como afirma Paraquett:

A escola, através da figura do professor, não pode deixar de considerar essa nova maneira de compreender e produzir sentidos, mas também não pode e não deve se esquecer que a mais significativa contribuição continua sendo a de possibilitar que esses aprendizes saibam ser críticos diante do que leem e compreendem, e que saibam valer-se da linguagem para suas necessidades e interesses na comunicação com seus pares. (PARAQUETT, 2009, p. 132).

No caso do espanhol, o fato de ser um idioma latino facilita sua compreensão, uma vez que há inúmeras semelhanças com o português. Quando elas são exploradas, num primeiro momento, acaba-se estimulando os alunos. Isso não exclui, obviamente, a necessidade de aprofundar os conhecimentos, mostrando que as semelhanças também podem induzir a erros, como no caso dos falsos cognatos ("falsos amigos").

Com relação à importância do ensino de espanhol nas escolas, Paraquett (2009) mostra que houve muitos avanços, mas há ainda muito que fazer, pois o espanhol, segunda maior língua de comunicação universal, ainda não teve sua real importância reconhecida pelo sistema educacional brasileiro.

A Lei de Diretrizes e Bases (LDB), de 1996 (Lei n 9. 394), no seu artigo 26, parágrafo 5º, definiu que "na parte diversificada do currículo será incluído, obrigatoriamente, a partir da 
quinta série, o ensino de pelo menos uma língua estrangeira moderna, cuja escolha ficará a cargo da comunidade escolar, dentro das possibilidades da instituição" (BRASIL, 1996). Na prática, observou-se uma predominância, nas escolas, da oferta do ensino de inglês como língua estrangeira, tanto no ensino fundamental quanto no médio.

Em 5 de agosto de 2005, foi sancionada a Lei $n^{\circ} 11.161$ (BRASIL, 2005), que tornou obrigatória, a partir de 2010, a oferta de espanhol no ensino médio. Isso, em princípio, atendia aos interesses do governo de maior integração do Brasil com as outras nações do Mercosul. Deve-se observar, no entanto, que a oferta de espanhol se tornou obrigatória, mas a matrícula era facultativa para os alunos.

Para piorar o quadro do ensino de espanhol no EM, a Lei no 13.415 (BRASIL, 2017), de 16 de fevereiro de 2017, em seu artigo $3^{\circ}$, parágrafo $4^{\circ}$, revogando a Lei 11.161 , determinou que, no ensino médio, os currículos "incluirão, obrigatoriamente, o estudo da língua inglesa e poderão ofertar outras línguas estrangeiras, em caráter optativo, preferencialmente o espanhol, de acordo com a disponibilidade de oferta, locais e horários definidos pelos sistemas de ensino". Mais uma vez, lamentavelmente, o espanhol continuou a ser apenas uma segunda opção na escola de ensino médio.

Observa-se, atualmente, uma movimentação por parte de faculdades de Letras e associações de professores de língua espanhola (como o \# Fica Espanhol ${ }^{5}$ ), que lançam mão de manifestos e publicações em campanhas nas redes sociais, para que o ensino de espanhol permaneça obrigatório no currículo de ensino médio. No entanto, até o momento, não houve resultados relevantes.

Em seus estudos, Catta Pretta (2008) chama a atenção para as dificuldades encontradas pelo professor de espanhol nas classes de EJA: material didático inadequado para a faixa etária, conteúdos descontextualizados, metodologias infantilizadas, além do despreparo de professores para atuar nessa modalidade. Todos esses fatores acabam por criar enormes dificuldades para que se realize um trabalho de boa qualidade em sala de aula. Nesse panorama pouco motivador, o professor de espanhol, sobretudo em turmas de EJA, precisa estar consciente de que seu trabalho exigirá muita criatividade, automotivação e determinação, apesar de todos os fatores desestimulantes.

\footnotetext{
${ }^{5}$ Maiores informações estão disponíveis em: https://pt-br.facebook.com/ficaespanhol/.
} 
Moraes (2010) também destaca que o professor de espanhol tem barreiras a enfrentar nas classes de EJA, e motivação para reflexão e aprendizagem precisam caminhar juntas. Isso requer do professor a capacidade de transformar medos e incertezas em sentimentos de segurança para que a aprendizagem possa acontecer.

Gadotti (2011) vê o professor como um profissional cujo trabalho é essencial na construção de uma sociedade mais justa. No entanto, entende que não será capaz de desenvolver uma prática satisfatória sem exercitar a empatia e a emoção. Uma ação pedagógica puramente técnica não atinge seus reais objetivos educativos.

Freire também entendia que a afetividade não está desvinculada da aprendizagem, da "cognoscibilidade" (FREIRE, 1996, p. 160). O educador também chama a atenção para a importância de se respeitarem os saberes trazidos pelos educandos para a sala de aula. Partindo desses conhecimentos, o professor passa a construir outros, levando os alunos a um ponto mais avançado, mais elaborado, com mais informações. É ensinar estimulando, conduzindo, ajudando a caminhar e trazendo à tona as reais capacidades desses alunos. Nesse processo, eles crescem e sua autoconfiança melhora, ampliando sua atuação social e cultural.

\section{Experiências pedagógicas em turmas de EJA do ensino médio}

Nesta parte do artigo, são relatadas algumas experiências pedagógicas de uma das autoras numa escola particular da cidade do Rio de Janeiro onde atuou como professora de espanhol na EJA-EM, de 2010 a 2017. Destaca-se inicialmente que os alunos moradores da periferia não pagavam mensalidade, pois o curso era subsidiado de forma integral pelo governo federal.

É importante mencionar que, de maneira geral, os educandos estabeleciam com os professores uma relação de admiração e respeito, capaz de construir laços de afetividade que facilitavam muito a aprendizagem. Ainda assim, havia um índice considerável de evasão, ao longo do ano, por motivos diversos, como horário de trabalho incompatível, hospitalização, problemas familiares, entre outros.

As turmas da EJA-EM na escola em questão eram multisseriadas, ou seja, eram colocados juntos, nas aulas de todas as disciplinas, alunos da primeira à terceira fase do ensino médio (cada fase, que durava um semestre, equivalia a um ano do ensino regular). Mesmo havendo três turmas de EJA-EM por semestre, as três eram assim compostas. As atividades, no 
entanto, eram diferentes para cada fase. Porém, os professores tinham autonomia para, quando julgassem conveniente, dar uma aula única - chamada de "aulão" - na qual os três grupos (fases) realizavam a mesma atividade, estudando um único tema. Esse tipo de aula promovia a integração mais efetiva entre os alunos e facilitava o trabalho dos docentes.

As experiências relatadas neste trabalho ocorreram em turmas com aproximadamente 30 estudantes cada na faixa etária entre 18 e 65 anos (mas, em 2016, havia uma aluna de 73 anos recém-alfabetizada). Como a maioria dos alunos das turmas era da $1^{\mathrm{a}}$ fase e, portanto, não havia estudado espanhol, para atender ao propósito de ensinar a todos de forma igualitária e melhor aproveitar o tempo, na maior parte das aulas, foi abordado um tema único. Os temas específicos para cada fase, em geral, tratavam de aspectos gramaticais e não envolviam debates ou atividades de maior interação, uma vez que cada grupo apresentava níveis diferentes de dificuldade. Cada sequência didática apresentada aqui foi desenvolvida em apenas uma aula (60 minutos), com exceção do projeto interdisciplinar, que abrangeu quatro aulas.

\section{Atividade 1: Campanha social (Campaña social)}

Foi mostrada aos alunos a imagem da Figura 1, de uma campanha social, com legenda em espanhol, para que exercitassem a compreensão leitora. Depois, foram feitas perguntas a serem respondidas em português. Em seguida, iniciou-se um debate sobre o tema da campanha.

Figura 1: Hacer la diferencia ${ }^{6}$

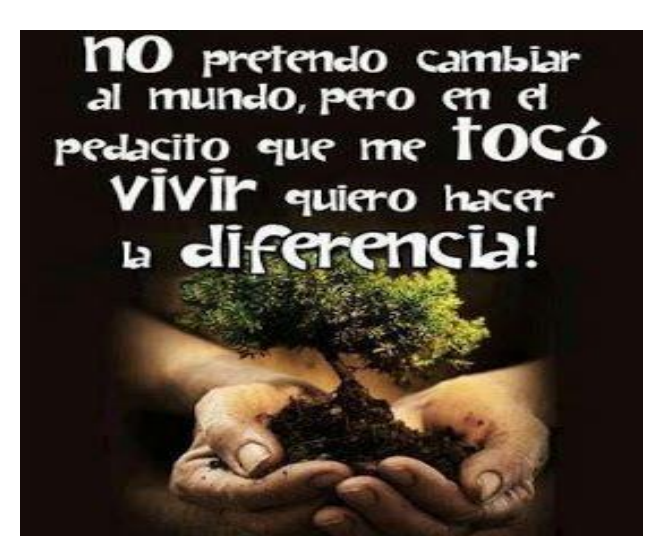

Fonte: Ross (s.d.).

\footnotetext{
${ }^{6}$ Tradução: "Não pretendo mudar o mundo, mas no pedacinho que me coube viver quero fazer a diferença."
} 
Com base na legenda da Figura 1, na parte gramatical, foi explorado o uso do sufixo ito como marca indicativa de diminutivo; o sentido do verbo cambiar e seus usos; o verbo tocar, em espanhol, dentro do contexto apresentado. Em seguida, os alunos foram levados a um debate, iniciado pelas seguintes perguntas: O que significa "fazer a diferença" onde vivemos? / É possível mudar as coisas ao nosso redor? / O que me cabe no processo de mudança?

Pelas respostas, observou-se uma certa consciência sobre o papel de cada um na construção da sociedade, contudo, os alunos, em suas falas, revelaram uma realidade cruel: a opressão sofrida por moradores de comunidades mais pobres do Rio de Janeiro. Traficantes e milicianos oprimem os moradores, ditando regras e criando um poder paralelo, deixando um rastro de medo e submissão, que reduz e, muitas vezes, anula a autonomia e o poder de escolha de quem mora na comunidade.

Considerando-se esse universo, no qual o poder de ação fica muito limitado, discutiu-se sobre o que é possível fazer, individualmente, ainda que pareça pouco, para que haja uma realidade mais justa. Obviamente o debate não pôde tomar grandes proporções, apesar do grande envolvimento dos alunos, uma vez que havia um objetivo pedagógico específico do ensino de língua espanhola a ser alcançado.

A proposta era apresentar conceitos gramaticais simples a partir de um texto em espanhol, além de estimular o debate e a construção de ideias sobre temas que fazem parte do cotidiano. Os resultados foram considerados satisfatórios, pois os alunos identificaram as grandes semelhanças entre espanhol e português, percebendo, de forma prática, que aprender espanhol é algo perfeitamente possível.

Além disso, os alunos participaram dos debates propostos, momento em que exercitaram a capacidade de ouvir opiniões diferentes, de expor suas vivências e defender suas ideias.

\section{Atividade 2: Filosofando em espanhol (Filosofando en español)}

Nessa sequência, foram apresentadas citações de pessoas famosas (Figuras 2 e 3). A partir dessas citações, foram explorados os aspectos gramaticais presentes nos textos, além de se trabalhar com conhecimentos gerais, visando promover um debate com os alunos. 
Figura $2^{7}$ - Citação de Martin Luther King

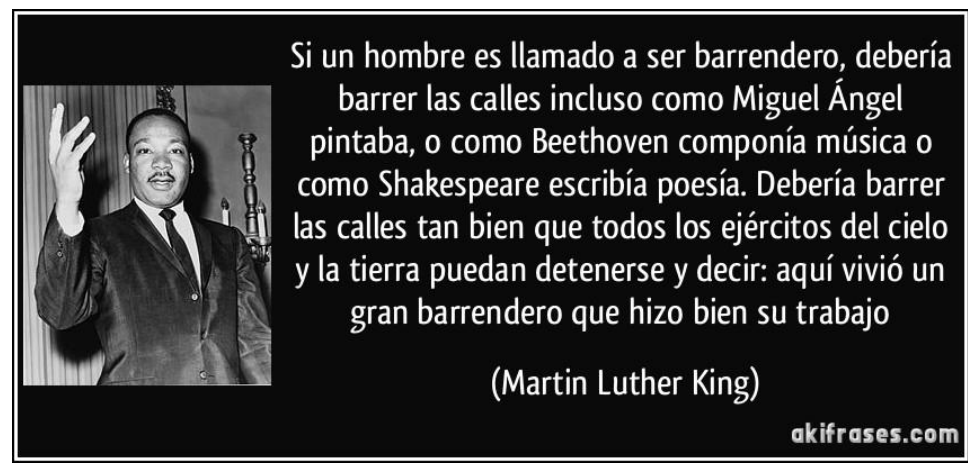

Fonte: Akifrases (s.d.)

Com base na primeira citação (Figura 2), após alguns breves comentários sobre as personalidades citadas (Michelangelo, Beethoven, Shakespeare, Martin Luther King), estimulou-se o debate sobre a importância de cada um fazer seu trabalho com dedicação e empenho, tornando-se referência em seu ofício, seja ele qual for. Na sequência, discutiu-se, de maneira breve, sobre Martin Luther King e sua importância para a história.

Quanto aos conceitos gramaticais, definiu-se o uso da contração del em espanhol, além das formas verbais no passado simples (hizo, vivió). Usando o texto como ponto de partida, explorou-se o conceito de trabalho, ampliando o vocabulário pertencente a esse campo semântico em espanhol.

Após o debate e o ensino do vocabulário novo, os alunos sugeriram nomes de pessoas que foram destaque em suas profissões. Os nomes das profissões citadas foram traduzidos para o espanhol: jogador de futebol (jugador de fútbol), cantor (cantante), ator (actor), etc. O tema envolveu os discentes, que participaram ativamente do exercício, numa tendência crescente de perceber o espanhol como uma língua possível de ser aprendida. No debate, os alunos participaram relatando suas experiências pessoais, e a atividade proporcionou uma reflexão sobre a importância da dedicação e do empenho ao exercermos uma atividade profissional.

Durante o debate, os alunos citaram, como exemplos de bons profissionais, alguns jogadores de futebol, como Messi, Neymar, Cristiano Ronaldo; e cantores como Alcione e Roberto Carlos. Após os exemplos dados, a professora chamou a atenção para outras áreas em que também há talentos, como política, artes plásticas, ações humanitárias, entre outros. $\mathrm{O}$

\footnotetext{
${ }^{7}$ Tradução: "Se um homem é chamado a ser gari, deveria varrer as ruas como Michelangelo pintava, ou como Beethoven compunha música, ou como Shakespeare escrevia poesia. Deveria varrer as ruas tão bem que todos os exércitos do céu e da terra possam parar e dizer: aqui viveu um grande gari que fez bem seu trabalho."
} 
objetivo era estimular a reflexão sobre o trabalho em suas múltiplas vertentes, enfatizando a relevância da dedicação, da disciplina e do empenho no exercício de qualquer ofício.

Figura 3 - Citação de Nelson Mandela ${ }^{8}$

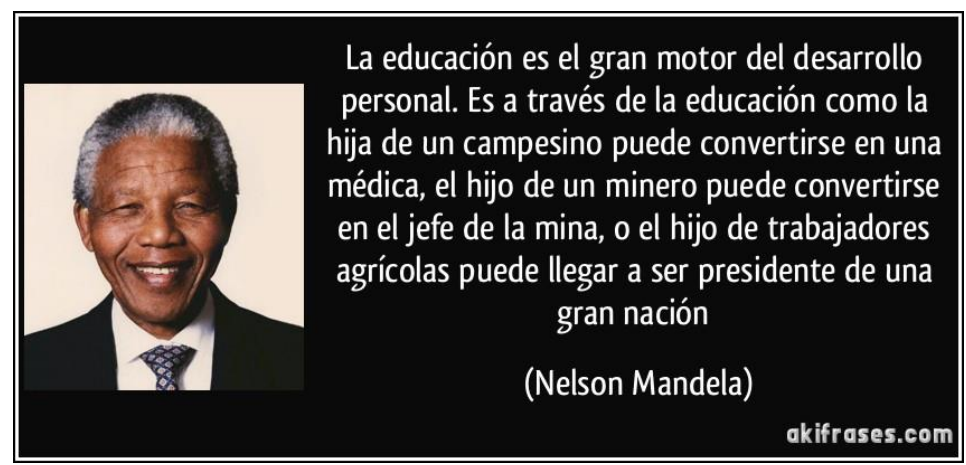

Fonte: Akifrases (s.d.).

As atividades com a segunda citação (Figura 3) foram iniciadas perguntando-se quem tinha sido Nelson Mandela. Alguns alunos conheciam a história de Mandela, pois o professor de História já havia falado sobre ele. Outros haviam assistido ao filme sobre sua vida. Discutiuse, brevemente, a importância dessa personalidade para o mundo e sua luta contra o racismo.

Partindo da palavra hijo, foi trabalhado o vocabulário de membros que compõem as famílias, como pai (padre), mãe (madre), neto (nieto), avô (abuelo), sobrinho (sobrino) etc. Na sequência, foi promovido um debate sobre o papel da educação na vida das pessoas. Os alunos foram estimulados a refletir sobre a importância de estarem na escola e de perceberem a educação como principal instrumento de luta por uma vida melhor e mais justa. A maioria demonstrou ter consciência da importância de retornar à escola e identificou o estudo como uma grande oportunidade para melhorar seus empregos e, consequentemente, ascender socialmente.

\section{Atividade 3: Ditos populares (Refranes)}

O objetivo dessa atividade foi explorar o universo da língua espanhola por meio do estudo de ditos populares, conhecidos em espanhol como refranes, relacionando-os ao conhecimento prévio dos alunos.

\footnotetext{
${ }^{8}$ Tradução: A educação é o grande motor de desenvolvimento pessoal. É através da educação que a filha de um camponês pode se transformar em médica, como o filho de um mineiro pode se transformar no chefe da mina, o filho de trabalhadores agrícolas pode chegar a ser o presidente de uma grande nação.
} 
Foram apresentados ditados populares em língua portuguesa que são de amplo conhecimento de todos, para, em seguida, estabelecer a relação com os ditos de língua espanhola. Assim, foi explorada a ideia de conhecimento popular como forma de expressão em qualquer idioma.

Iniciou-se a aula escrevendo-se no quadro o seguinte: Água mole em pedra dura, tanto bate / Diz-me com quem andas e

Oralmente, foi pedido aos alunos que completassem as frases; o que foi feito com precisão. Ao completarem a primeira - Água mole em pedra dura, tanto bate até que fura. -, a professora perguntou sobre o sentido desse dito popular, ou seja, que conceito ou ideia ele pretende expressar como verdade. Os discentes fizeram a correspondência com a perseverança, a insistência para se conseguir alguma coisa. Na segunda frase, completaram Diz-me com quem andas e te direi quem és, e responderam que as companhias são determinantes no comportamento das pessoas; o tipo de amizade que temos diz muito sobre quem somos na verdade.

Na segunda parte da atividade, a turma foi dividida em duplas. Foi distribuída uma lista com ditos populares em espanhol (refranes) para que os alunos atendessem o seguinte roteiro:

1 - Identifiquem qual ideia cada frase pretende transmitir;

2 - Encontrem em português seu correspondente, ou seja, o dito popular que encerra a mesma ideia. Exemplos:

a. Espanhol: A caballo regalado no se miran los dientes.

Português: Cavalo dado não se olham os dentes.

Mensagem: Não devemos procurar defeito nos presentes que ganhamos.

b. Espanhol: No le busques cinco pies al gato.

Português: Não procure chifre em cabeça de cavalo.

Mensagem: Não perca tempo procurando algo que não existe.

Os alunos foram levados a perceber que não se tratava de uma simples tradução de frases, mas sim uma versão em português para ideia ou conceito semelhante. Essa atividade seguiu o que o propõem as $\mathrm{PCN}+$ : 
Há elementos textuais em língua estrangeira que podem estar relacionados a seus equivalentes na língua materna ou a outros códigos estrangeiros, no âmbito morfológico, sintático ou semântico. A correlação possibilita a compreensão desses elementos. Por exemplo: [...]. O estudo de provérbios também fornece bons índices do processo de correlação, que ultrapassa a questão linguística e é revelador de diferentes culturas e visões de mundo. (BRASIL, 2007, p. 94).

No primeiro momento, os alunos se mostraram motivados pela discussão sobre sabedoria popular. Na tarefa de interpretação, alguns tentaram fazer uma simples tradução das frases. Então foi preciso a professora esclarecer o que estava sendo pedido efetivamente.

Ao final da tarefa, os discentes revelaram que era interessante perceber que cada idioma usa elementos diferentes para expressar uma mesma ideia e que tinham ficado curiosos para descobrir o correspondente em português de cada frase em espanhol.

Foram trabalhados os conhecimentos prévios dos alunos em relação aos ditos populares, ao mesmo tempo em que foi demonstrado, de maneira prática, que a tradução envolve conceitos e ideias e não somente palavras. Os educandos participaram com interesse e curiosidade, estimulados pela busca de significados.

\section{Atividade 4: Leitura e debate (Lectura y debate)}

Foi apresentado à turma uma reportagem do jornal $A B C$ (2011), tratando do desperdício de alimentos na Espanha, intitulado "Los españoles tiran a la basura $20 \%$ de la comida que compran"9 (SANCHES, 2011).

Em um primeiro momento, o texto foi lido pela professora, em voz alta, para que fosse trabalhado o vocabulário novo. Ela perguntou se os alunos percebiam qual era o assunto do texto apenas pelo título. Alguns começaram a levantar hipóteses sobre o sentido do verbo tirar em espanhol, relacionando-o com o verbo tirar em português, porém, ao testar suas hipóteses na frase, perceberam que o sentido não poderia ser o mesmo. Na sequência, novas hipóteses foram feitas até que se chegasse ao significado do verbo: jogar fora.

Nesse exercício de inferência, que foi repetido com outros vocábulos do texto, os alunos foram levados a perceber que é possível deduzir o sentido de palavras desconhecidas em espanhol considerando o contexto, sem que seja necessário o uso do dicionário em todas as situações.

\footnotetext{
${ }^{9}$ Tradução: Os espanhóis jogam fora $20 \%$ da comida que compram.
} 
A parte gramatical pôde ser bem explorada, assim como as técnicas de leitura interativa. Os alunos participaram das atividades e debateram o tema do texto, porém o interesse não foi grande, considerando que o desperdício de alimentos não fazia parte da vida deles. Alguns, inclusive, explicaram técnicas de como conservar os alimentos por mais tempo, revelando um bom conhecimento prévio sobre o assunto.

Essa foi uma experiência bastante enriquecedora para a professora, que aprendeu com os alunos. Conforme afirma Freire (1996, p. 23), “quem ensina aprende ao ensinar e quem aprende ensina ao aprender".

\section{Projeto interdisciplinar: Américas}

Inicialmente é importante esclarecer que "projeto interdisciplinar", neste trabalho, é entendido como a atividade pedagógica que envolve várias disciplinas. É um trabalho no qual um tema gerador serve de pesquisa para que os alunos desenvolvam conceitos inerentes a diferentes áreas de conhecimento. O projeto interdisciplinar Américas foi realizado pelos professores de espanhol, inglês, artes e geografia e envolveu três turmas (com alunos das três fases em cada) de EJA-EM.

Cada turma se dividiu em dois grupos e cada grupo teve que pesquisar sobre um país de língua espanhola e outro de língua inglesa. Os países foram indicados pelos professores de espanhol e de inglês. Todas as turmas do ensino médio participaram do projeto e assistiram a todas as apresentações para que houvesse um compartilhamento das informações e os alunos conhecessem as informações sobre todos os países pesquisados.

O trabalho seguiu o seguinte roteiro: 1 - Que país é este? (Nome, localização geográfica, população, idioma, religião); 2 - Quais os principais pontos turísticos? (Escolher 3 pontos); 3 - Como é sua gastronomia? (Citar 2 pratos típicos); 4 - Que tipo de música tocam e dançam? (Ritmos musicais predominantes); 5 - Curiosidades culturais (peculiaridade de hábitos, comidas, religião etc.); 6 - Um grande nome das artes (pintura, literatura, música etc.).

A prática docente por projetos oferece ótimas oportunidades de aprendizado, e a língua estrangeira tem importante papel nesse processo, conforme assinalam os $\mathrm{PCN}+$ :

A língua estrangeira ocupa posição privilegiada no currículo por servir como "ferramenta" a todas as outras disciplinas, facilitando a articulação entre áreas e oferecendo múltiplos suportes para várias atividades e projetos. $\mathrm{O}$ 
que ocorre nos projetos interdisciplinares, ainda que de modo simulado, é uma antecipação do que acontecerá na futura vida social do aluno, no mundo do trabalho e no âmbito acadêmico, se for prosseguir seus estudos. (BRASIL, 2007, p. 91).

Tendo em conta os objetivos do projeto interdisciplinar, esse trabalho foi considerado de ótimo resultado, pois os alunos, ao realizarem suas pesquisas, acessaram informações relativas a países distantes, com suas peculiaridades, culturas e hábitos, ampliando, assim, seus conhecimentos, atendendo ao que está proposto nos PCN+ (BRASIL, 2007).

As atividades possibilitaram ainda, como pontos positivos, a autonomia dos alunos nas pesquisas, o compartilhamento das informações e o exercício do trabalho em equipe. Houve grande envolvimento e comprometimento dos educandos na elaboração dos trabalhos, o que se refletiu positivamente no resultado final.

\section{Reflexões sobre a prática}

Nesse trabalho, mostrou-se, preliminarmente, a necessidade de se fazer uma trajetória de convencimento dos alunos para perceberem que estudar uma língua estrangeira não é algo "muito difícil".

Já no primeiro contato com os educandos, é importante que o professor demonstre a importância da língua espanhola no panorama mundial e apresente suas aplicações práticas. Os alunos devem perceber a abrangência do conhecimento de espanhol em sua formação: ele possibilita a comunicação virtual com nativos de países hispânicos; a compreensão de músicas em língua espanhola; a leitura de notícias, reportagens, anúncios, quadrinhos, poemas, dentre outros gêneros textuais em espanhol. Essas habilidades servem de acesso a novas culturas e ajudam os alunos a ter uma visão clara da funcionalidade do aprendizado do idioma.

Terminada essa abordagem preliminar, o segundo argumento para que se convençam da possibilidade do aprendizado de espanhol é o fato de ser uma língua latina parecida com o português. A apresentação de um texto de fácil compreensão e com grande número de palavras transparentes, em um primeiro exercício com a língua espanhola, é um bom instrumento para começar a quebrar o paradigma de que aprender espanhol seja difícil. Num segundo momento, entretanto, deve-se mostrar que as semelhanças também podem induzir a erros, como no caso dos "falsos amigos" ou falsos cognatos. 
Ao final das primeiras aulas, conduzidas de forma interativa, os alunos de EJA apresentarão mais autoconfiança, pois se sentirão capazes de dominar um novo conhecimento. $\mathrm{O}$ sentimento de valorização pessoal poderá provocar um aumento de sua autoestima, o que os fará reformular crenças limitantes, convidando-os a novos desafios no campo do saber, melhorando, consequentemente, seu rendimento escolar.

Com as atividades propostas e seus respectivos resultados, pôde-se perceber que os alunos da EJA precisam efetivamente envolver-se com o tema tratado em sala de aula para que a aprendizagem seja realmente significativa. As atividades que partiram desse princípio tiveram bom resultado, provocando motivação e interesse. Entretanto, quando o tema gerador não se referia a algo que fizesse parte do cotidiano deles, havia desinteresse.

Faz-se imprescindível que a discussão dos temas da aula parta de um conhecimento prévio, para que os educandos se sintam estimulados a participar, dar opiniões, transformando a sala de aula em um lugar de total interação. Como afirma Ausubel (1982, p. 137), “o fator singular mais importante que influencia na aprendizagem é aquilo que o aprendiz já conhece.” Não há como ignorar esse aspecto preponderante, principalmente quando estamos trabalhando com público adulto, com grande experiência de vida e personalidade praticamente definida.

O diálogo entre o professor e seus alunos é sempre importante no processo pedagógico, porém, nas turmas de EJA, ele se torna imprescindível, sob pena de a aprendizagem perder-se e os objetivos não serem atingidos. Sempre que os alunos se envolveram nas atividades aqui relatadas, participando, dialogando, debatendo ideias, ao final, conseguiram ter a percepção do espanhol como algo interessante de aprender e, o mais importante, como um saber acessível.

É essencial, além disso, que o ensino do espanhol como língua estrangeira tenha os textos como ponto de partida. De maneira mais específica, poderia, ainda, incluir o trabalho com as características dos gêneros textuais. Assim, o professor poderia levar os alunos a desenvolver conhecimentos gramaticais e habilidades linguísticas, além de promover a reflexão sobre temas relevantes à formação discente, como está proposto nos $\mathrm{PCN}+$ :

O trabalho de leitura e interpretação textual permite ainda o desenvolvimento de conceitos como cultura, linguagens, contexto, identificação de temática, pesquisa. Além disso, mobiliza competências relativas à identificação das intenções, da visão de mundo da cultura do produtor dos enunciados. Para que abram esse leque de possibilidades, os textos em língua estrangeira selecionados devem funcionar como veículo das 
diversidades culturais, levantando questões sociais ligadas a preconceitos e desigualdades - cuja abordagem pode e deve ser feita em articulação com outras disciplinas. $\mathrm{O}$ trabalho envolvendo temática sociocultural é igualmente importante para o desenvolvimento de competências nas quais a linguagem é fonte de legitimação de acordos e de condutas a serem avalizadas ou não. (BRASIL, 2007, p. 113).

Seguindo essa trajetória na condução da aprendizagem, os alunos descobrem que são capazes de dominar um novo conhecimento, mesmo que tenham entrado na escola receosos do contrário. Essa descoberta faz deles educandos mais autoconfiantes, aptos a perceber que o espaço escolar é um lugar onde podem e devem estar, onde conseguirão se desenvolver, reformular ideias, fazer novas amizades, criar vínculos.

É fato que cada disciplina abarca um universo próprio, um olhar para o mundo sob uma determinada ótica e, portanto, tem sua especial contribuição na formação discente, contudo, os saberes estão sempre interligados. O espanhol é uma língua de comunicação universal, o que a torna um instrumento de interação entre pessoas de diferentes nacionalidades, culturas, etnias, ampliando horizontes e abrindo oportunidades.

Assim, quando os alunos se veem capazes de aprender espanhol, processo que inicialmente lhes parecia impossível, há um aumento da sua autoestima. Isso ajuda a torná-los mais aptos a vencer desafios da aprendizagem, o que contribuirá de forma significativa para seu rendimento em todas as demais disciplinas, além de colaborar para seu sentimento de pertencimento em relação à escola. Alunos adultos autoconfiantes tendem a progredir muito mais, motivam-se para os estudos, estimulam seus companheiros a seguir nos estudos, tornam-se multiplicadores positivos em todo o ambiente escolar.

Todos esses aspectos positivos cooperam para a comprovação da importância do ensino de Espanhol nas escolas. Dessa forma, é possível contestar as leis educacionais que colocam em segundo plano o ensino dessa língua.

\section{Considerações finais}

A partir da análise das experiências aqui relatadas, pode-se observar que, na EJA, para que a aprendizagem seja significativa, as práticas em sala de aula devem considerar o conhecimento prévio dos alunos, as experiências de vida e a visão de mundo que já trazem. Ao apresentar um novo conceito, o professor precisa estabelecer uma relação direta entre o novo e o que os alunos já sabem. 
Além disso, é essencial que os educandos recebam o estímulo individual e coletivo para se tornarem ativos no processo ensino-aprendizagem. Isso terá impacto direto no bom rendimento escolar e fortalecerá a autoestima do alunado e o desejo de seguir os estudos. É de grande relevância, também, promover o trabalho em grupo, no qual os que sabem mais ajudam os que sabem menos. Essa ação pedagógica valoriza a cooperação e a solidariedade, fortalece o sentido de pertencimento ao grupo e interfere positivamente no rendimento.

No caso do ensino de espanhol para as classes de EJA, é perfeitamente possível reconfigurar as crenças iniciais que dificultam a aprendizagem. Por meio de atividades criativas e que abordem temas relevantes, os alunos poderão perceber que são capazes de aprender o espanhol, inclusive por se tratar de uma língua-irmã do português.

Reforça-se aqui que o ensino de espanhol nas turmas de EJA poderá ajudar a melhorar a inclusão social dos alunos, e isso se refletirá, inevitavelmente, no seu rendimento escolar de maneira global e na sua atuação na sociedade.

O professor de espanhol, ainda que tenha que lidar com dificuldades mencionadas nesse artigo, precisa conscientizar-se da sua importânca como educador e agente transformador. Ele leva aos alunos algo muito valioso - uma língua estrangeira - que servirá de instrumento de acesso a inúmeros outros conhecimentos e culturas.

\section{Referências}

AKIFRASES. Disponível em: https://akifrases.com/frase/118212. Acesso em: 20 dez. 2018

AUSUBEL, D. P. A aprendizagem significativa. São Paulo: Moraes, 1982.

BARCELOS, A. M. F. Reflexões acerca da mudança de crenças sobre o ensino de aprendizagem de línguas. Rev. Bras. Linguística Aplicada, Belo Horizonte, v. 7, n. 2, p. 110-138, 2007. Doi: 10.1590/S1984-63982007000200006.

BRASIL. Lei $\mathrm{n}^{\circ}$. 13.415, de 16 de fevereiro de 2017. Altera as Leis $\mathrm{n}^{\circ}$ 9.394, de 20 de dezembro de 1996, que estabelece as diretrizes e bases da educação nacional, e 11.494, de 20 de junho 2007, que regulamenta o Fundo de Manutenção e Desenvolvimento da Educação Básica e de Valorização dos Profissionais da Educação, a Consolidação das Leis do Trabalho - CLT, aprovada pelo Decreto-Lei $n^{\circ} 5.452$, de $1^{\circ}$ de maio de 1943, e o Decreto-Lei $n^{\circ} 236$, de 28 de fevereiro de 1967; revoga a Lei $\mathrm{n}^{\circ}$ 11.161, de 5 de agosto de 2005; e institui a Política de Fomento à Implementação de Escolas de Ensino Médio em Tempo Integral. Brasília, DF: Presidência da República/Casa Civil, [2017]. Disponível em: http://www.planalto.gov.br/ccivil_03/Ato2015-2018/2017/Lei/L13415.htm\#art22. Acesso em: 20 dez. 2018. 
BRASIL. Ministério da Educação. Orientações educacionais complementares aos parâmetros curriculares nacionais $(\mathbf{P C N}+)$ : linguagens, códigos e suas tecnologias. Brasília, DF: MEC/SEB, 2007. Disponível em: http://portal.mec.gov.br/seb/arquivos/pdf/linguagens02.pdf. Acesso em: 7 nov. 2018.

BRASIL. Ministério da Educação. Orientações curriculares para o ensino médio: linguagens, códigos e suas tecnologias. v. 1. Brasília, DF: MEC/SEB, 2006. Disponível em: http://portal.mec.gov.br/seb/arquivos/pdf/book_volume_01_internet.pdf. Acesso em: 7 nov. 2018.

BRASIL. Lei $n^{\circ} 11.161$, de 5 de agosto de 2005. Dispõe sobre o ensino de língua espanhola. Brasília, DF: Presidência da República/Casa Civil, [2005]. Disponível em: http://www.planalto.gov.br/ccivil_03/_ato2004-2006/2005/lei/111161.htm. Acesso em: 20 dez. 2018.

BRASIL. Ministério da Educação. Parecer CNE/CEB n 11/2000, de 10 de maio de 2000. Dispõe sobre as Diretrizes Curriculares Nacionais para a Educação de Jovens e Adultos. Brasília, DF: CNE/CBE, 2000. Disponível em: http://portal.mec.gov.br/cne/arquivos/pdf/pceb011_00.pdf. Acesso em: 28 nov. 2018.

BRASIL. Ministério da Educação. Lei de Diretrizes e Bases da Educação Nacional. Lei no 9394/96, de 20 de dezembro de 1996. Estabelece as diretrizes e bases da educação nacional. Brasília, DF: Presidência da República/Casa Civil, [1996]. Disponível em: http://www.planalto.gov.br/ccivil_03/leis/19394.htm. Acesso em: 01 jun. 2019.

FREIRE, P. Pedagogia da autonomia: saberes necessários à prática educativa. 25. ed. São Paulo: Paz e Terra, 1996.

GADOTTI, M. Ser professor, ser educador. In: GADOTTI, M. Boniteza de um sonho: ensinar-e-aprender com sentido. 2 ed. São Paulo: Instituto Paulo Freire, 2011.

GADOTTI, M. Educação popular e educação ao longo da vida. Disponível em: https://www.paulofreire.org/images/pdfs/Educacao_Popular_e_ELV_Gadotti.pdf. Acesso em: 26 nov. 2018.

LABELLA-SÁNCHEZ, N. La enseñanza del español en la educación de jóvenes y adultos como posibilitadora de inserción social. In: BARROS, C.S.; COSTA, E.G.M. (org.). Se hace camino al andar: reflexões em torno do ensino de espanhol na escola. Belo Horizonte: FALE/UFMG, 2012.

MORAES, F. S. Ensino de língua espanhola: desafios à atuação docente. 2010. 139 f. Dissertação (Mestrado em Educação) - Faculdade de Ciências Humanas, Universidade Metodista de Piracicaba, Piracicaba, 2010.

PARAQUETT, M. O papel que cumprimos os professores de espanhol como língua estrangeira (E/LE) no Brasil. Caderno de Letras da UFF: Dossiê Diálogos Interamericanos, Niterói, n. 38, p. 123-137, 2009. Disponível em: http://www.cadernosdeletras.uff.br/joomla/images/stories/edicoes/38/artigo7.pdf. Acesso em: 10 fev. 2019. 
PRETA, L. M. C. Leitura e ensino/aprendizagem de espanhol como língua estrangeira na educação de jovens e adultos. 2008. Dissertação (Mestrado em Letras) - Instituto de Letras, Universidade Federal Fluminense, Niterói, 2008.

ROSS, N. Pinterest. Disponível em: https://br.pinterest.com/pin/468304061222861906/. Acesso em: 20 nov. 2018

SÁNCHEZ, C. Los españoles tiran a la basura $20 \%$ de la comida que compran. ABC.es: Sociedad, Madrid, 4 maio 2011. Disponível em: https://www.abc.es/20110503/sociedad/abciestudio-basura-201105031625.html. Acesso em: 4 ago. 2018.

Submetido em 17 de março de 2019

Aprovado em 3 de junho de 2019. 